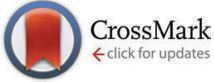

Cite this: J. Mater. Chem. C, 2015, 3, 7870

Received 2nd April 2015

Accepted 7th May 2015

DOI: $10.1039 / \mathrm{c} 5 \mathrm{tc00930h}$

www.rsc.org/MaterialsC

\title{
Vacuum-evaporable spin-crossover complexes: physicochemical properties in the crystalline bulk and in thin films deposited from the gas phase
}

\author{
H. Naggert, ${ }^{a}$ J. Rudnik, ${ }^{a}$ L. Kipgen, ${ }^{\mathrm{b}}$ M. Bernien, ${ }^{\mathrm{b}}$ F. Nickel, ${ }^{\mathrm{b}}$ L. M. Arruda, ${ }^{\mathrm{b}}$ W. Kuch, ${ }^{\mathrm{b}}$ \\ C. Näther ${ }^{a}$ and F. Tuczek*a
}

\begin{abstract}
Four analogues of the spin-crossover complex $\left[\mathrm{Fe}\left(\mathrm{H}_{2} \mathrm{Bpz}_{2}\right)_{2}\left(\right.\right.$ phen)] $\left(\mathrm{H}_{2} \mathrm{Bpz}_{2}=\right.$ dihydrobis(pyrazolyl)borate; 2$)$ containing functionalized 1,10-phenanthroline (phen) ligands have been prepared; i.e., $\left[\mathrm{Fe}\left(\mathrm{H}_{2} \mathrm{Bpz} \mathrm{Z}_{2}(\mathrm{~L})\right]\right.$, $\mathrm{L}=$ 4-methyl-1,10-phenanthroline (3), 5-chloro-1,10-phenanthroline (4), 4,7-dichloro-1,10-phenanthroline (5), and 4,7-dimethyl-1,10-phenanthroline (6). The systems are investigated by magnetic susceptibility measurements and a range of spectroscopies in the solid state and in thin films obtained by physical vapour deposition (PVD). Thermal as well as light-induced SCO behaviour is observed for 3-6 in the films. By contrast, thermal SCO in the solid state occurs only for $\mathbf{3}$ and $\mathbf{4}$ but is absent for $\mathbf{5}$ and $\mathbf{6}$. These findings are discussed in the light of cooperative and intermolecular interactions.
\end{abstract}

\section{Introduction}

The development of molecular switches opens up new applications in spintronics and data storage. ${ }^{1,2}$ An important aspect of this research area refers to spin-state switching, which is based on electronic bistability in spin-crossover (SCO) compounds. ${ }^{3}$ As shown by us and others, the SCO complexes $\left[\mathrm{Fe}\left(\mathrm{H}_{2} \mathrm{Bpz}_{2}\right)_{2}(\mathrm{~L})\right]$ $\left(\mathrm{H}_{2} \mathrm{Bpz}_{2}=\right.$ dihydrobis(pyrazolyl)borate, $\mathrm{L}=2,2^{\prime}$-bipyridine (bipy, 1) or 1,10-phenanthroline (phen, 2) $)^{4-6}$ can be used for the preparation of high-quality thin films by deposition from the gas phase. ${ }^{1,7-10}$ In these compounds the iron(II) center is surrounded by bidentate ligands with the positive charge being compensated by two $\mathrm{H}_{2} \mathrm{Bpz}_{2}$-ligands (Fig. 1). Upon cooling from room temperature to $160 \mathrm{~K}$, spin crossover from ${ }^{5} \mathrm{~T}_{2 \mathrm{~g}}$ to ${ }^{1} \mathrm{~A}_{1 \mathrm{~g}}$ occurs, and below $50 \mathrm{~K}$ light-induced spin state switching (LIESST) into a metastable ${ }^{5} \mathrm{~T}_{2 \mathrm{~g}}$ state is possible.

Recently, we performed valence-band photoemission studies on ultrathin films ( $\sim 6$ monolayers) on $\mathrm{Au}(111)$ of $\left[\mathrm{Fe}\left(\mathrm{H}_{2} \mathrm{Bpz}_{2}\right)_{2}(\right.$ phen $\left.)\right]$ (2) deposited from the gas phase. ${ }^{11}$ Vacuum-UV light induced excited spin state trapping (VUVIESST) was observed at temperatures below $50 \mathrm{~K}$. By additionally irradiating the sample with

\footnotetext{
${ }^{a}$ Institute of Inorganic Chemistry, Christian-Albrechts-University Kiel, Max-Eyth-Str. 2, 24118 Kiel, Germany. E-mail: ftuczek@ac.uni-kiel.de

${ }^{b}$ Institute for Experimental Physics, Freie Universität Berlin, Arnimallee 14, 14195 Berlin, Germany

$\dagger$ Dedicated to Dr Dénes Lajos Nagy on the occasion of his 70th anniversary. ‡ Electronic supplementary information (ESI) available: Crystallographic data, XRD-powder patterns, and infrared spectra of bulk/film and XA spectra. CCDC 1054496, 1054497 and 1054498. For ESI and crystallographic data in CIF or other electronic format see DOI: $10.1039 / \mathrm{c} 5 \mathrm{tc} 00930 \mathrm{~h}$
}

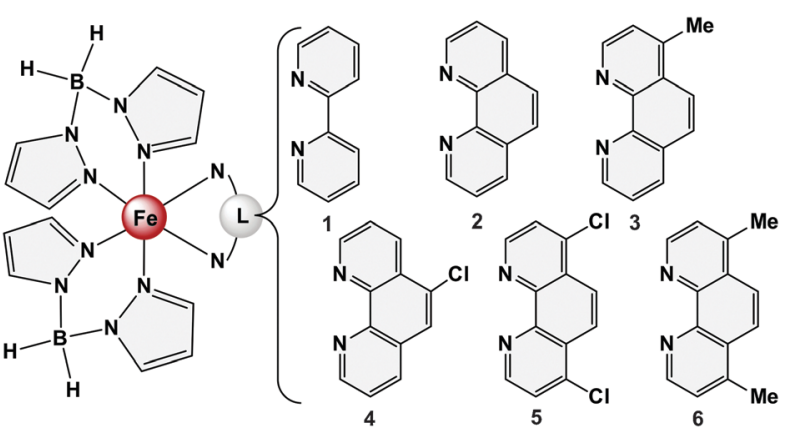

Fig. 1 The complexes $\left[\mathrm{Fe}\left(\mathrm{H}_{2} \mathrm{Bpz}_{2}\right)_{2}(\mathrm{~L})\right]$ investigated in this work, based on functionalized 1,10-phenanthroline ligands (3-6).

green light the steady-state spin-transition temperature at which $\gamma_{\mathrm{HS}}=\gamma_{\mathrm{LS}}=0.5$ could be shifted from $37 \mathrm{~K}$ to $99 \mathrm{~K}$. Moreover, mono- and submonolayers of 2 were prepared by thermal evaporation and investigated by high-resolution STMtopography at $5 \mathrm{~K}$. Electron-induced excited spin state trapping (ELIESST) was observed for single molecules of 2 in a double layer on Au(111). STS indicated a change in the HOMO-LUMOgap from $\sim 2 \mathrm{eV}$ in the low-spin state to a much smaller value in the high-spin state, in agreement with DFT calculations. ${ }^{1,11}$ The composition of the first layer of 2 on $\mathrm{Au}(111)$ was further investigated by thermal and angle-dependent near-edge X-ray absorption fine structure (NEXAFS). Importantly, an isotropic Fe $\mathrm{L}_{2,3}$ XA spectrum was obtained that reflected a high-spin state over the full temperature range, and angle dependent nitrogen K-edge XAS indicated an orientation of 1,10-phenanthroline of about $16^{\circ}$ with respect to the surface. This information and 
further high-resolution STM data showed that in a submonolayer on $\mathrm{Au}(111)$ the complex decomposes into the bidendate ligand 1,10-phenanthroline and high-spin $\mathrm{Fe}\left(\mathrm{H}_{2} \mathrm{Bpz}_{2}\right)_{2} \cdot{ }^{9}$ This suggests that the first double layer of $\left[\mathrm{Fe}\left(\mathrm{H}_{2} \mathrm{Bpz}_{2}\right)_{2}\right.$ (phen)] (2) on $\mathrm{Au}(111)$ identified by STM (see above) consists of 1,10-phenanthroline molecules resulting from decomposition of 2 on this surface.

One possible strategy to prevent decomposition of $\left[\mathrm{Fe}\left(\mathrm{H}_{2} \mathrm{Bpz}_{2}\right)_{2}\right.$ (phen)] (2) on $\mathrm{Au}(111)$ is to reduce the interaction of this complex with the surface. This may be achieved by attaching substituents to the phen and bipy ligands. In the literature $\left[\mathrm{Fe}\left(\mathrm{H}_{2} \mathrm{Bpz}_{2}\right)_{2}(\mathrm{~L})\right]$ complexes with annulated bipyridyl co-ligands or bipy/phen ligands functionalized by diarylethene or $\pi$-radical ligands have been reported $;^{12,13}$ however, the properties of these systems with respect to thermal deposition have not been described. Herein, we investigate the influence of a chemical modification of the 1,10-phenanthroline ligands on the physicochemical properties of $\left[\mathrm{Fe}\left(\mathrm{H}_{2} \mathrm{Bpz}\right)_{2}\right)_{2}$ (phen) $]$ (2). In particular, we want to study how methyl and chlorine substituents on the 1,10-phenanthroline ligand of 2 affect its SCO properties in the bulk and in thin films (Fig. 1). To this end we have prepared four analogues of 2 containing functionalized 1,10-phenanthroline ligands; i.e., $\left[\mathrm{Fe}\left(\mathrm{H}_{2} \mathrm{Bpz}_{2}\right)_{2}(\mathrm{~L})\right], \mathrm{L}=$ 4-methyl-1,10-phenanthroline (3), 5-chloro-1,10-phenanthroline (4), 4,7-dichloro-1,10phenanthroline (5), and 4,7-dimethyl-1,10-phenanthroline (6). Information on the spin crossover behaviour of 3-6 is derived from temperature-dependent susceptibility measurements, Mössbauer spectroscopy and single crystal structure determination. Moreover, vacuum deposited films of 3-6 have been fabricated by thermal evaporation, and the thermal SCO, LIESST and reverse-LIESST characteristics ${ }^{14}$ are studied by temperature-dependent optical transmission spectroscopy. Finally, infrared and resonance Raman spectroscopy as well as synchrotron-based XA-spectroscopy are performed on microcrystalline powders and vacuum-deposited films. The results are discussed in the light of cooperative and intermolecular interactions which are present in the crystalline bulk material but absent in vacuum-deposited films.

\section{Results and discussion}

\section{X-ray crystallography}

Following the method reported for the synthesis of $\mathbf{1}$ and 2 microcrystalline powders were obtained for compounds 3-6 with methanol as the solvent. ${ }^{4,15}$ Attempts to crystallize these complexes from other solvents did not yield suitable single crystals either; only for 6 single crystals could be obtained using a toluene- $n$-hexane mixture. Compound 6.0.5 $\mathrm{C}_{7} \mathrm{H}_{8}$ crystallizes in the space group $P-1$ with $Z=2$ molecules in the unit cell. The asymmetric unit consists of one complex in the general position and one half of a toluene molecule, which is located on the center of inversion and shows a random orientation. At room-temperature the disorder could not be refined; therefore, additional datasets were measured at $200 \mathrm{~K}$ and $110 \mathrm{~K}$ (ESI, $\$$ Table S1).

In the crystal structure of $6 \cdot 0.5 \mathrm{C}_{7} \mathrm{H}_{8}$ the $\mathrm{Fe}(\mathrm{II})$ cations are coordinated by two $\mathrm{H}_{2} \mathrm{Bpz}_{2}$ anions and one 4,7-dimethyl-1,10phenanthroline ligand within a slightly distorted octahedral
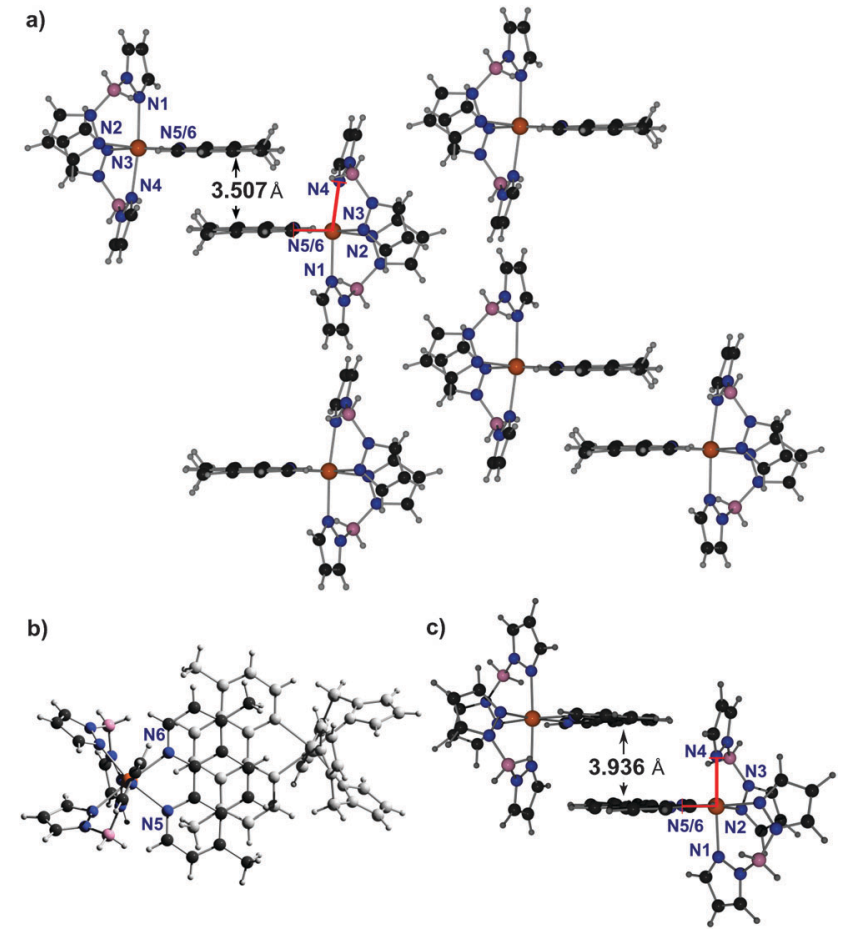

Fig. 2 1D stacking motifs in $6 \cdot 0.5 \mathrm{C}_{7} \mathrm{H}_{8}$ at $293 \mathrm{~K}$ in the side view (a) and in the top view (b). For comparison compound $\mathbf{2}$ (c) taken from Real et al. ${ }^{4}$ Color code: C (black), H (grey), B (pink), N (blue), Fe (orange) and toluene (not shown).

geometry. The FeN-bond distances are between 2.222-2.170 at $293 \mathrm{~K}$ and thus are in a range expected for $\mathrm{Fe}(\mathrm{II})$ in a highspin configuration. Upon cooling only small changes in the Fe-N distances are observed (2.2210-2.1790 $\AA$ at $200 \mathrm{~K}$ and 2.220-2.1693 $\AA$ at $110 \mathrm{~K}$ ), indicating that no SCO occurs in this temperature range. The discrete complexes are arranged into dimers by intermolecular face-to-face $\pi-\pi$-interactions between 4,7-dimethyl-1,10-phenanthroline ligands of neighbouring complexes (Fig. 2a, b). The interplanar distance between these ligands amounts to $3.507 \AA$ A. Similar dimers have also been observed by Real et al. in the crystal structure of 2 , which exhibits SCO with a $T_{1 / 2}$ of $164 \mathrm{~K}$. However, in 2 this distance is $\sim 10 \%$ longer (3.936 ̊; Fig. 2c). ${ }^{4}$ Interestingly, Halcrow et al. reported an interplanar distance of $3.485 \AA$ and $3.459 \AA$ between the phenazine ligands of $\left[\mathrm{Fe}\left(\mathrm{H}_{2} \mathrm{Bpz}\right)_{2}\left(\operatorname{dipyrido}\left[3,2-a: 2^{\prime}, 3^{\prime}(6,7,8,9-\right.\right.\right.$ tetrahydro)phenazine)]], which remains in the high-spin state between $300 \mathrm{~K}$ and $70 \mathrm{~K}$, suggesting that a short dimer-dimer distance might be correlated with a lack of SCO behavior. ${ }^{12}$ The short phen-phen distance in $\mathbf{6} \cdot \mathbf{0 . 5} \mathrm{C}_{7} \mathrm{H}_{8}$ appears to be the result of perfect stacking (Fig. 2b). In particular the methyl groups of one phen ligand are exactly positioned above the center of one $\mathrm{C}_{6}$ ring in a neighbouring phen ligand such that the two phen ligands (and the attached complex units) get closely interlocked. In 6.0.5 $\mathrm{C}_{7} \mathrm{H}_{8}$ the angle $\phi\left(\mathrm{N}_{1}-\mathrm{Fe}-\mathrm{N}_{4}\right)$ of 97.76 is significantly enlarged with respect to $2\left(\phi\left(\mathrm{N}_{1}-\mathrm{Fe}-\mathrm{N}_{4}\right)=92.47\right)$, leading to a distortion of the $\mathrm{FeN}_{6}$ core. This may also be a result of strong intermolecular face-to-face $\pi-\pi$-interactions, leading to steric repulsion between a 4,7-dimethyl-1,10-phenanthroline 
ligand and a neighboring complex ( $c f$. Fig. 2a, red). A similar repulsion appears to be absent in 2 (Fig. 2c red) where the interplanar phen-phen distance is longer.

While no single crystal data could be obtained for 3-6, all of these compounds were characterized by X-ray powder diffractometry ( $c f$. ESI, $\$ \mathrm{~S} 2$ ). Not surprisingly, the XRPD pattern of 6. $0.5 \mathrm{C}_{7} \mathrm{H}_{8}$ does not correspond to that of 6 . However, the XRPD pattern of compound 6 is very similar to that of 5 , indicating that both compounds are isotypic. This can be explained by the fact that in compound $\mathbf{6}$ the two chloro substituents in $\mathbf{5}$ are exchanged by methyl groups which exhibit similar van der Waals radii (the so-called chloro-methyl exchange rule). ${ }^{16}$

\section{Thermal spin-crossover in the solid state}

In order to analyse the spin state of iron(II) centres in compounds 3-6 magnetic susceptibility measurements were performed. Plots of the product $\chi_{\mathrm{M}} T v$ s. the temperature $(T)$ are given in Fig. 3; the thermal transition temperatures $T_{1 / 2}$ are summarized in Table 1 . Compound 4 shows a fairly steep spin transition from $0.19 \mathrm{~cm}^{3} \mathrm{~K} \mathrm{~mol}^{-1}$ at $10 \mathrm{~K}$ to $3.54 \mathrm{~cm}^{3} \mathrm{~K} \mathrm{~mol}^{-1}$ at $300 \mathrm{~K}$ with a $T_{1 / 2}$ of $151 \mathrm{~K}$. For 3 , a less abrupt spin transition from $0.21 \mathrm{~cm}^{3} \mathrm{~K} \mathrm{~mol}^{-1}$ at $10 \mathrm{~K}$ to $3.54 \mathrm{~cm}^{3} \mathrm{~K} \mathrm{~mol}^{-1}$ at $300 \mathrm{~K}$ with a transition temperature of $T_{1 / 2}=165 \mathrm{~K}$ is found. Both 3 and 4 have about $5 \%$ high-spin contribution at low temperatures. Compounds 5 and $\mathbf{6}$, in contrast, are predominantly high spin; i.e., the susceptibility sharply increases in the range below $20 \mathrm{~K}$ and remains at values around $3.5 \mathrm{~cm}^{3} \mathrm{~K} \mathrm{~mol}^{-1}$ for 5 and 6 upon further increasing the temperature to $300 \mathrm{~K}$. The hightemperature $\chi_{\mathrm{M}} T$ values of 3-6 are considerably larger than expected

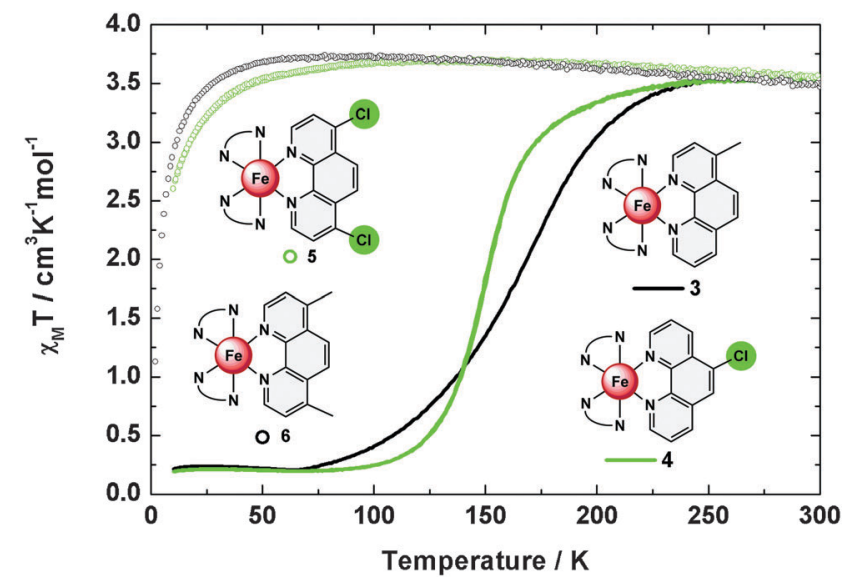

Fig. $3 \chi_{M} T$ vs. $T$ curves of $\mathbf{3}$ (black line), $\mathbf{4}$ (green line), $\mathbf{5}$ (green circle) and 6 (black circle).

Table 1 Thermal transition temperatures \& Mössbauer fitting parameters

\begin{tabular}{|c|c|c|c|c|c|}
\hline \multirow[b]{2}{*}{ \# } & \multirow[b]{2}{*}{$T_{1 / 2}[\mathrm{~K}]$} & \multicolumn{2}{|l|}{$300 \mathrm{~K}$} & \multicolumn{2}{|l|}{$80 \mathrm{~K}$} \\
\hline & & $\Delta\left[\mathrm{mm} \mathrm{s}^{-1}\right]$ & $\Delta E_{\mathrm{Q}}\left[\mathrm{mm} \mathrm{s}^{-1}\right]$ & $\delta\left[\mathrm{mm} \mathrm{s}^{-1}\right]$ & $\Delta E_{\mathrm{Q}}\left[\mathrm{mm} \mathrm{s}^{-1}\right]$ \\
\hline 3 & 165 & 1.00 & 1.53 & 0.53 & 0.48 ( $4 \% \mathrm{HS})$ \\
\hline 4 & 151 & 1.00 & 1.55 & 0.53 & $0.40(5 \% \mathrm{HS})$ \\
\hline 5 & HS & 1.00 & 1.80 & 1.15 & 2.40 (99\% HS) \\
\hline 6 & HS & 0.96 & 1.72 & 1.09 & $2.35(100 \% \mathrm{HS})$ \\
\hline
\end{tabular}

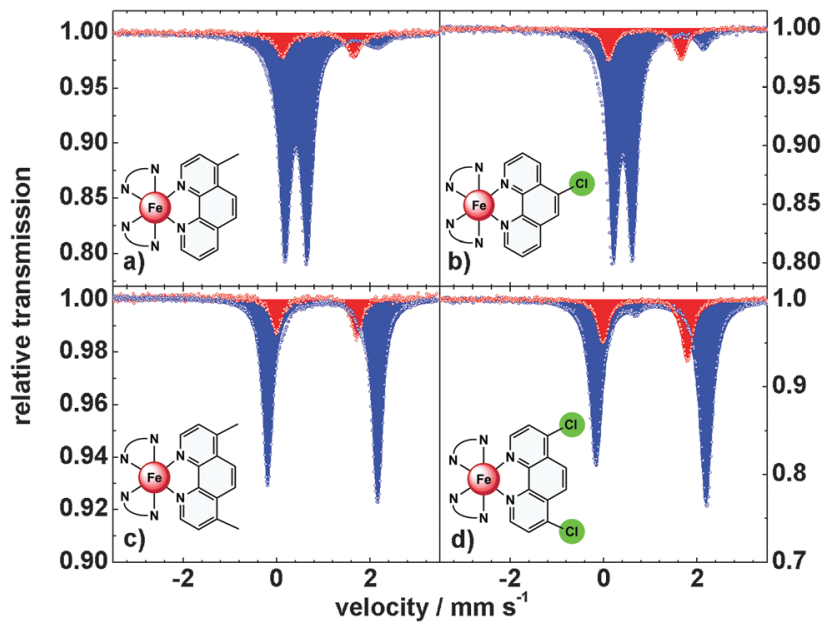

Fig. 4 Mössbauer spectra of $\mathbf{3}$ (a), 4 (b), 6 (c) and 5 (d) at $300 \mathrm{~K}$ (red) and $80 \mathrm{~K}$ (blue).

for pure $S=2$ systems $\left(\chi_{\mathrm{M}} T=3.02 \mathrm{~cm}^{3} \mathrm{~K} \mathrm{~mol}^{-1}\right)$, which is caused by spin orbit coupling.

To obtain further information on the spin-state of the iron centers, Mössbauer spectra were recorded at $300 \mathrm{~K}$ and $80 \mathrm{~K}$ (Fig. 4 and Table 1). At $300 \mathrm{~K}$ the spectra of 3 and 4 with monosubstituted 1,10-phenanthroline ligands show a doublet with $\delta=1.00 \mathrm{~mm} \mathrm{~s}^{-1}$, indicative of high-spin iron(II) centers. At $80 \mathrm{~K}$ the isomer shift decreases to $\delta=0.53 \mathrm{~mm} \mathrm{~s}^{-1}$, typical for low spin iron centers. In both compounds an amount of $\sim 5 \%$ high spin species is observed at $80 \mathrm{~K}$, in agreement with the magnetic data. Compounds 5 and $\mathbf{6}$ with difunctionalized ligands exhibit isomer shifts of $\delta=1.00$ and $0.96 \mathrm{~mm} \mathrm{~s}^{-1}$, resp., at $300 \mathrm{~K}$ and $\delta=1.15$ and $1.09 \mathrm{~mm} \mathrm{~s}^{-1}$, resp., at $80 \mathrm{~K}$, indicative of $\mathrm{HS}$ configurations at both temperatures.

The thermal spin crossover in the solid state thus can be summarized as follows: compounds $\mathbf{3}$ and $\mathbf{4}$ are typical spin crossover compounds like compound $2\left(T_{1 / 2}=163 \mathrm{~K}\right){ }^{4,7}$ In 4 , the electron withdrawing effect of the chlorine group lowers the transition temperature to $T_{1 / 2}=151 \mathrm{~K}$ while the transition temperature is increased to $T_{1 / 2}=165 \mathrm{~K}$ in 3 due to the electron-donating effect of the methyl group. In the case of the difunctionalized compounds 5 and $\mathbf{6}$ the ${ }^{5} \mathrm{~T}_{2}$ state is stabilized down to $20 \mathrm{~K}$; i.e., the spin transition of the parent complex 2 becomes largely suppressed in the crystalline bulk material.

\section{Spin-crossover in vacuum-deposited films}

All compounds can be evaporated in a vacuum to obtain films on quartz substrates. Infrared spectra of the films are found to be very similar to those recorded for the bulk material (ESI, $¥ \mathrm{~S} 3$ and S4); an example is given in Fig. 5 for compound 6. The symmetric and antisymmetric $\mathrm{B}-\mathrm{H}$ vibrations, e.g., are detectable in the bulk as well as in the film at $\nu_{\text {asym }}(\mathrm{B}-\mathrm{H})=2416 \mathrm{~cm}^{-1}$ and $\nu_{\text {sym }}(\mathrm{B}-\mathrm{H})=2277 \mathrm{~cm}^{-1}$, which clearly indicates a successful thermal deposition without decomposition. Similar observations apply to compounds $\mathbf{3 - 5}$. To monitor the spin crossover in the films temperature dependent UV/vis absorption spectra 
a)

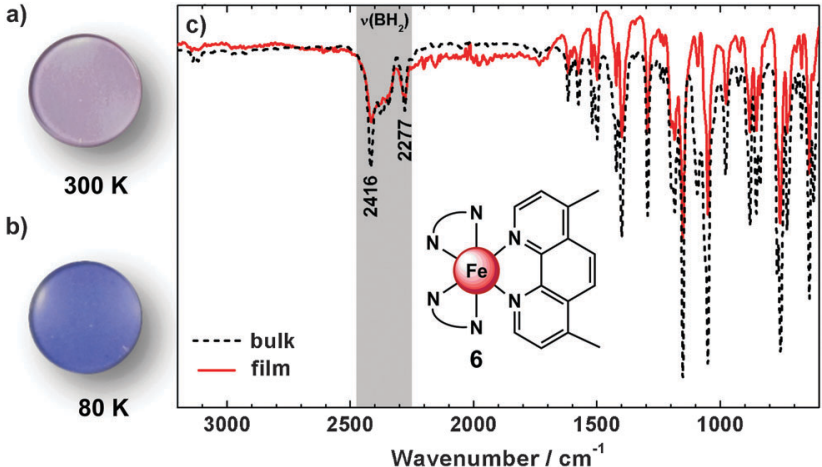

Fig. 5 Physical vapour deposited film on a quartz disc of 6 at $300 \mathrm{~K}(\mathrm{a})$ and $80 \mathrm{~K}$ (b). FT-IR spectra (c) of the bulk material (black dotted) and the vacuum deposited material (red) of 6 at $300 \mathrm{~K}$.
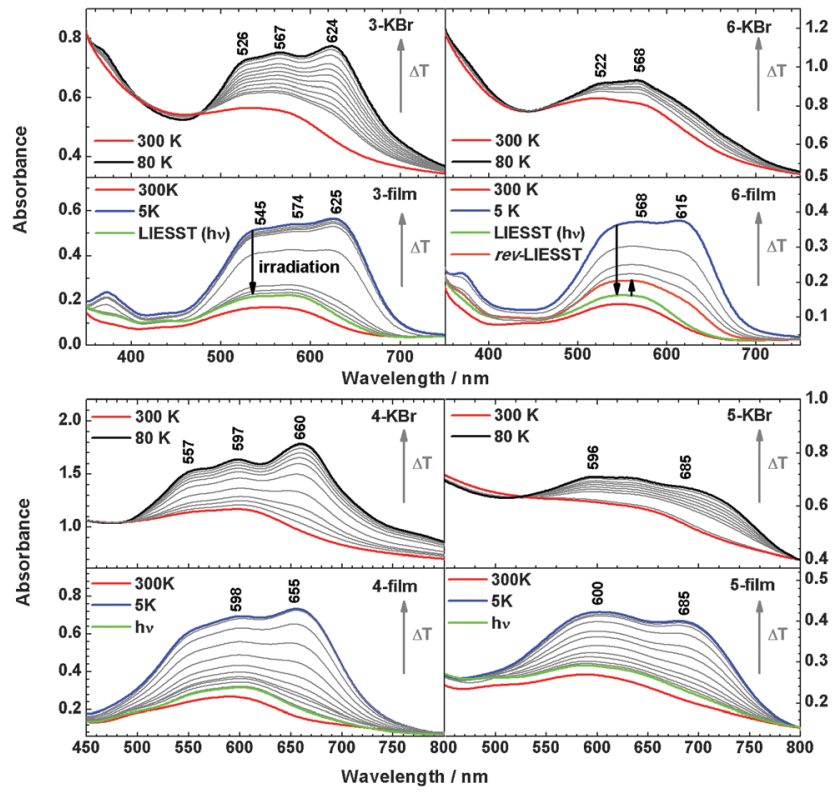

Fig. 6 Temperature dependent UV/Vis absorption spectra of 3, 4, 5 and $\mathbf{6}$ in $\mathrm{KBr}$-pellets and film on a quartz disc. LIESST and reverse-LIESST are demonstrated in films under irradiation at $519 \mathrm{~nm}$ (green lines) or $810 \mathrm{~nm}$ (orange line).

were measured. For comparison microcrystalline powders of 3-6 dispersed in KBr-pellets were investigated (Fig. 6).

The metal-to-ligand charge-transfer (MLCT) bands of 2 at $500-650 \mathrm{~nm}$ are more intense in the LS than in the HS state. ${ }^{3,7}$ For 3, the MLCT band centred at $550 \mathrm{~nm}$ at $300 \mathrm{~K}$ similarly evolves into a more intense three-band pattern with maxima at 526, 567 and $624 \mathrm{~nm}$ at $80 \mathrm{~K}$, both in $\mathrm{KBr}$ and in the film. Similar observations are made for 4 . Importantly, the films of 3 and 4 exhibit the LIESST effect; i.e., at $5 \mathrm{~K}$ the low-spin state can be converted back to the high-spin state by irradiation at $519 \mathrm{~nm}$ for 5 minutes. For 6 , the MLCT band exhibits two maxima ( 522 and $568 \mathrm{~nm}$ ) at $300 \mathrm{~K}$ in $\mathrm{KBr}$, but the spectrum exhibits little change upon decreasing the temperature to $80 \mathrm{~K}$. This is consistent with the lack of SCO determined by magnetic susceptibility measurements for this system (see above).

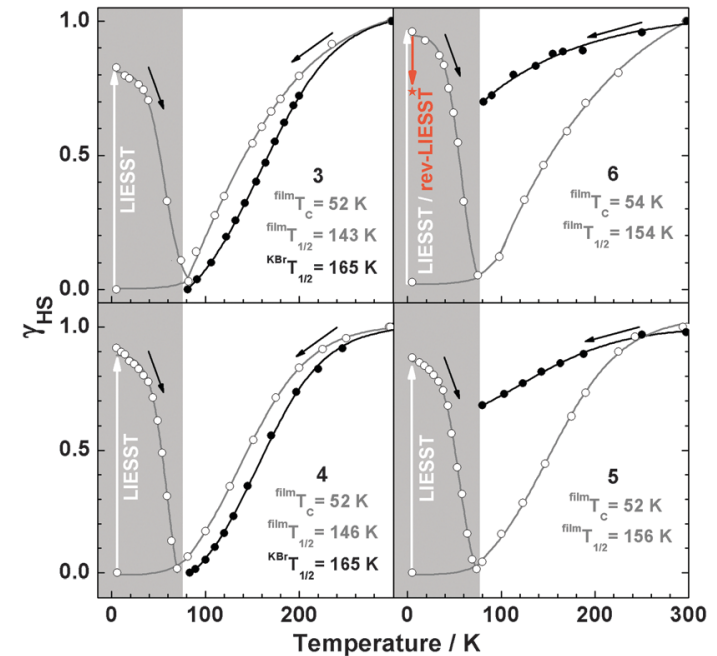

Fig. 7 High-spin fraction $\gamma_{\mathrm{HS}}$ of 3, 4, 5 and $\mathbf{6}$ determined by UV/Vis spectroscopy in film (black open circles) and bulk in $\mathrm{KBr}$ (black full circles). Temperature profiles (black arrow), LIESST (white arrow) and reverseLIESST (orange arrow) are clarified.

Surprisingly, however, in the vacuum deposited film of 6 the MLCT band at $550 \mathrm{~nm}(300 \mathrm{~K})$ evolves into a much more intense twoband pattern (maxima at 568 and $615 \mathrm{~nm}$ ) at $5 \mathrm{~K}$, indicating a transition from the high spin to the low spin state.

By irradiation at $519 \mathrm{~nm}$ at $5 \mathrm{~K}$, the low-spin state can be converted to the high spin state, and this spin-state switching can be reversed to a certain degree by irradiation at $810 \mathrm{~nm}$ (reverseLIESST, see below). Compound 5 in $\mathrm{KBr}$ shows less intense bands at $596 \mathrm{~nm}$ and $685 \mathrm{~nm}$, whereas in films the intensity at $600 \mathrm{~nm}$ and $685 \mathrm{~nm}$ increases to the same level as in KBr. In Fig. 7 the highspin fraction calculated by the method applied previously ${ }^{7,17}$ is plotted $v s$. the temperature. In the bulk material of 5 and $\mathbf{6}$ in $\mathrm{KBr}$ the spin transition is largely suppressed. On the other hand, all films show thermal SCO behaviour and exhibit the LIESST-effect by irradiation at $519 \mathrm{~nm}$ for $5 \mathrm{~min}$ at $5 \mathrm{~K}$. For all systems, $\gamma_{\mathrm{HS}}$ values of $\sim 82-96 \%$ can be achieved. The critical LIESST-temperatures are $T_{\mathrm{C}}=52-54 \mathrm{~K}$, which are 8-10 K higher than that for $2 .^{5,7}$ The reverse-LIESST effect is demonstrated in $\mathbf{6}$ under irradiation at $810 \mathrm{~nm}$ for $30 \mathrm{~min}$, leading to a decrease of $\gamma_{\mathrm{HS}}$ from 96 to $74 \%$. The thermal spin transition of $\mathbf{4}$ is more gradual in the vacuumdeposited film than in the bulk material (cf. Fig. 3) which can be attributed to a decrease of cooperative interactions. ${ }^{14,18}$ This has already been noticed in our study of the parent compound $\left[\mathrm{Fe}\left(\mathrm{H}_{2} \mathrm{Bpz}_{2}\right)(\right.$ phen $\left.)\right](2){ }^{7}$ As a matter of fact, the thermal spin crossover of a film of $\mathbf{2}$ is very similar to that of $\mathbf{2}$ embedded in polystyrene (ESI, $¥$ Fig. S5). The observation of a spin transition in the films of $\mathbf{5}$ and $\mathbf{6}$ also appears to be due to a reduction of cooperative or intermolecular interactions which apparently "lock" these systems in the high-spin state in the crystalline bulk material. ${ }^{19}$

In order to obtain more information on the electronic states of 6 XA spectra at the iron $\mathrm{L}_{2,3}$ edges were recorded. ${ }^{9,20}$ Fig. 8 shows the temperature variation for a thin film $(\sim 4 \mathrm{ML})$ on HOPG (a) and a bulk material crimped in indium foil (b); roomtemperature spectra are plotted in red and $80 \mathrm{~K}$ spectra in blue. 


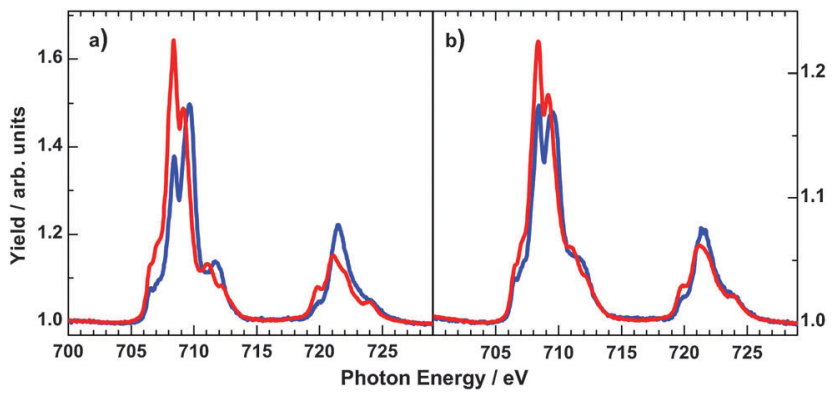

Fig. 8 Temperature-dependent iron $L_{2,3}$ XA spectra of $4 \mathrm{ML}$ of 6 on HOPG (a) and bulk powder sample crimped in indium foil (b) at $300 \mathrm{~K}$ (red lines) and $80 \mathrm{~K}$ (blue lines).

At $300 \mathrm{~K}$, the iron $\mathrm{L}_{3}$ edge exhibits a typical double-peak structure with maxima at $708.4 \mathrm{eV}$ and $709.2 \mathrm{eV}$, indicative of $\mathrm{HS}-\mathrm{Fe}(\mathrm{II}) .{ }^{9}{ }^{9} 20 \mathrm{At}$ $80 \mathrm{~K}$, the intensity of the $708.4 \mathrm{eV}$ peak decreases, and the peak at $709.2 \mathrm{eV}$ shifts to $709.4 \mathrm{eV}$ together with a satellite peak that shifts from $711.0 \mathrm{eV}$ to $711.7 \mathrm{eV}$. There is still a significant contribution of the $708.4 \mathrm{eV}$ peak, characteristic for the high-spin state. The thermal spin crossover thus is not complete. Nevertheless, the SCO is more pronounced in the thin film than in the bulk powder sample, in agreement with the results from optical absorption spectroscopy. High-spin fractions were determined by fitting measured spectra with theoretical spectra obtained by multiplet calculations ( $c f$. ESI, $\$ \mathrm{~S} 6$ ). In the thin film of $\sim 4 \mathrm{ML}$, the HS fraction determined in this way decreases from $\sim 100 \%$ at $300 \mathrm{~K}$ to about $58 \%$ at $80 \mathrm{~K}$, whereas for the bulk sample, the HS fraction is reduced from $94 \%$ at $300 \mathrm{~K}$ to $73 \%$ at $80 \mathrm{~K}$. From difference spectra we also conclude that the change of $\gamma_{\mathrm{HS}}$ is $\sim 2$ times larger in the film than in the bulk material of 6 . It must be stressed that Mössbauer and magnetic measurements (see above) showed no contribution of the LS state at $300 \mathrm{~K}$. However, Moliner et al. reported a LS fraction of $15 \%$ in $2 .{ }^{5}$ In Fig. 9 the N-K XA spectrum of the thin film of 6 on HOPG, measured at $300 \mathrm{~K}$, is shown along with the spectrum of the bulk material finely scratched onto an indium foil. The two spectra closely resemble each other, again confirming the integrity of the evaporated compound.

\section{Raman spectroscopy of the bulk material and thin films}

To further investigate the spin transition, temperature dependent resonance Raman spectra with excitation wavelengths of

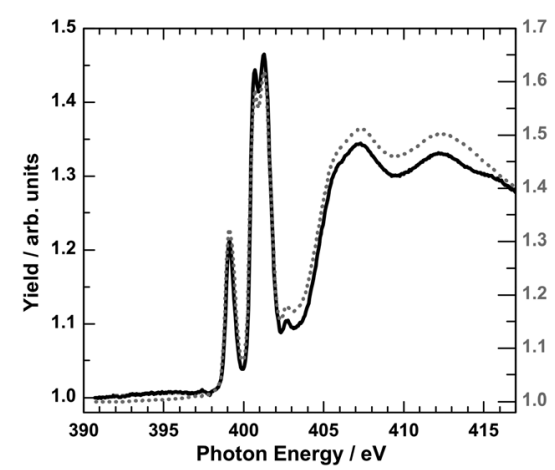

Fig. $9 \mathrm{~N}-\mathrm{K} X \mathrm{XA}$ spectrum of $4 \mathrm{ML}$ of $\mathbf{6}$ on HOPG (black line) with respect to the bulk material finely scratched onto indium foil (grey dotted line) at $300 \mathrm{~K}$.

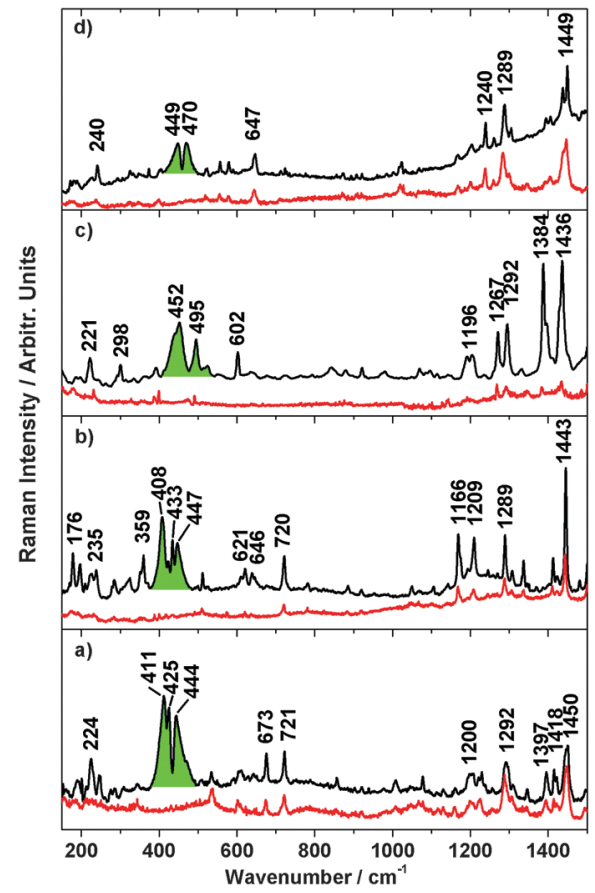

Fig. 10 Resonance Raman $\left(\lambda_{\text {exc }}=647 \mathrm{~nm}\right.$ ) of $\mathbf{3}(\mathrm{a}), \mathbf{4}(\mathrm{b}), \mathbf{5}(\mathrm{c}), \mathbf{6}(\mathrm{d})$ at $300 \mathrm{~K}$ (red lines), $20 \mathrm{~K}$ (black lines) and electronic transition coloured in green.

$\lambda_{\text {exc }}=514 \mathrm{~nm}$ and $647 \mathrm{~nm}$ were measured. In Fig. 10 the Raman spectra of 3-6 dispersed in $\mathrm{KBr}$ at $300 \mathrm{~K}$ and $25 \mathrm{~K}$ are shown. At $300 \mathrm{~K}$, the high-spin spectra show numerous peaks for metalligand and interligand vibrations of the pyrazole and phenanthroline units. At $25 \mathrm{~K}$, these peaks get more intense; moreover, a broad and intense band with maxima at $411 \mathrm{~cm}^{-1}, 425 \mathrm{~cm}^{-1}$ and $444 \mathrm{~cm}^{-1}$ appears for 3 (green). Similar bands are observed for 4 (maxima at $408 \mathrm{~cm}^{-1}, 433 \mathrm{~cm}^{-1}$ and $447 \mathrm{~cm}^{-1}$ ), 5 (maxima at $452 \mathrm{~cm}^{-1}$ and $495 \mathrm{~cm}^{-1}$ ) and 6 (maxima at $449 \mathrm{~cm}^{-1}$ and $470 \mathrm{~cm}^{-1}$ ).

Raman spectra of a similar quality could not be obtained for the vacuum-deposited films of $\mathbf{3 - 6}$, in contrast to the parent compounds 1 and 2. Temperature-dependent Raman spectra of 1 and 2 recorded for the bulk material dispersed in $\mathrm{KBr}$ are shown in Fig. 11a and b (upper three traces) along with the corresponding thin-film spectra recorded at $25 \mathrm{~K}$ (bottom traces). Small differences between the $300 \mathrm{~K}$ spectra (high-spin; red) and the $100 \mathrm{~K}$ (low-spin; blue) are detectable; a full analysis of these data will be presented elsewhere. At $25 \mathrm{~K}$ (black traces) broad intense bands emerge at $460 \mathrm{~cm}^{-1}$ for 1 and at $\sim 420 \mathrm{~cm}^{-1}$ (maxima at 401, 426 and $441 \mathrm{~cm}^{-1}$ ) for 2 (green), in analogy to compounds 3-6 (Fig. 10). Importantly, these features are absent in vacuum-deposited films of $\mathbf{1}$ and $\mathbf{2}$ (bottom traces of Fig. 11). We attribute these bands to electronic Raman transitions. In the case of compound 2 the electronic transition obviously combines with vibrational modes of the high-spin state; i.e., peaks appearing at 417 and $434 \mathrm{~cm}^{-1}$ in the room temperature spectrum (Fig. 11b red) are present as dips in the $25 \mathrm{~K}$ spectrum (Fig. 11b, black). For further clarification Fig. 11c shows a Gaussian profile centred at $417 \mathrm{~cm}^{-1}$ representing the electronic Raman transition. It is seen that the $25 \mathrm{~K}$ spectrum exhibits minima at positions where the room-temperature spectrum (enlarged) has maxima. 

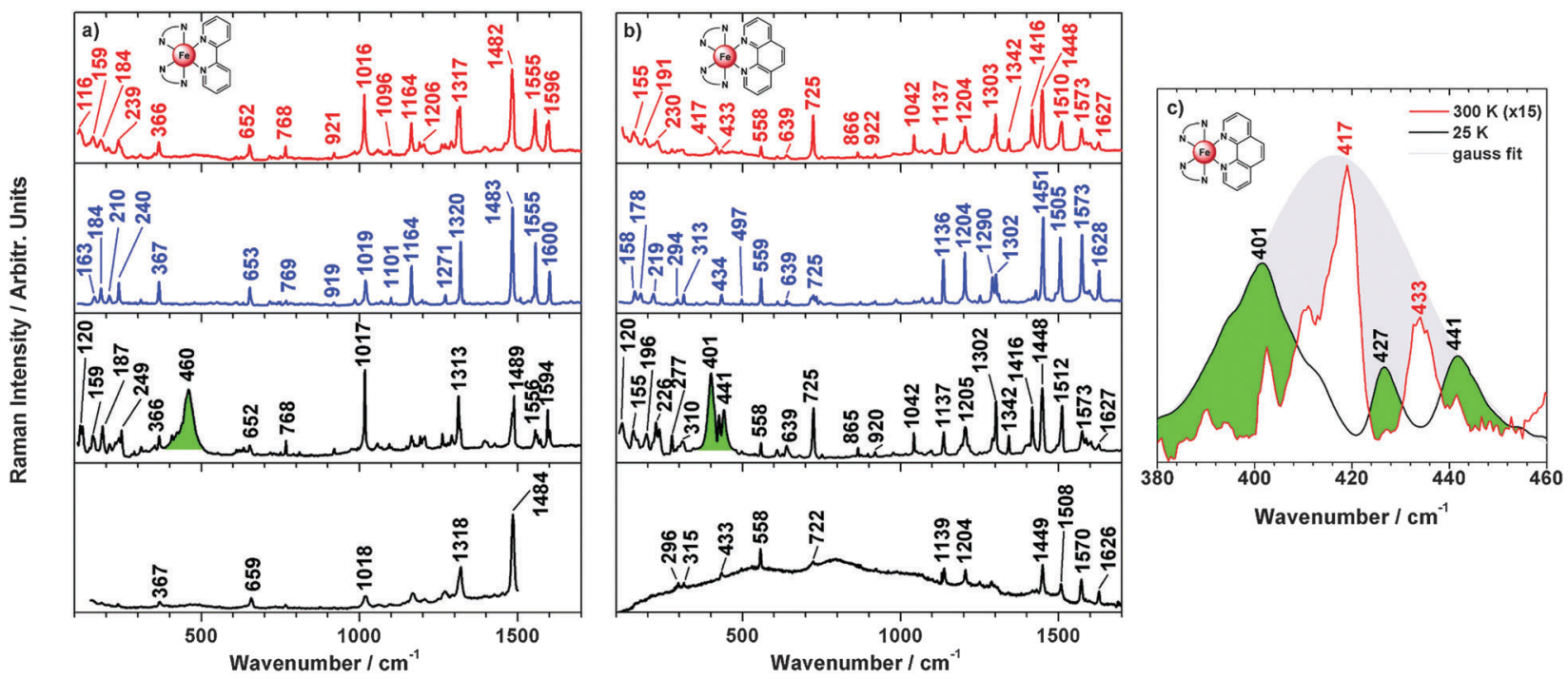

Fig. 11 Temperature dependence of the resonance Raman $\left(\lambda_{\text {exc }}=647 \mathrm{~nm}\right.$ ) spectra of 1 (a) and 2 (b) at $300 \mathrm{~K}$ (red lines), $100 \mathrm{~K}$ (blue lines) and $25 \mathrm{~K}$ (black lines) in $\mathrm{KBr}$-pellet and vacuum deposited film $\left(\lambda_{\text {exc }}=514 \mathrm{~nm}\right.$ ) on Au/Ti/glass at $25 \mathrm{~K}$ (black lines, bottom). Resonance Raman $\left(\lambda_{\text {exc }}=647 \mathrm{~nm}\right)$ of 2 (c) in $\mathrm{KBr}$ at $300 \mathrm{~K}$ (red line, 15× enlarged), $25 \mathrm{~K}$ (black line) and the Gaussian profile of the $25 \mathrm{~K}$ spectrum (grey area). The electronic Raman transition bands are coloured in green.

Such antiresonance phenomena occur when transitions to a continuum of states are superposed with transitions to discrete levels. ${ }^{21}$ This appears to be the case for compound 2 as the electronic Raman band is much broader than the vibrational peaks. Similar considerations apply to compounds 3-6, exhibiting electronic Raman bands with complex band shapes as well (Fig. 10). For compound 1, on the other hand, no vibrational peaks are present in the region of the electronic Raman transition; therefore this band exhibits a conventional band shape without antiresonance dips (Fig. 11a, green).

To explain the observation of an electronic Raman effect in the crystalline bulk material we assume that excitation through the Raman laser populates the high-spin state and an electronic transition occurs within the ${ }^{5} \mathrm{~T}_{2 \mathrm{~g}}$ state split by low symmetry into a $|\xi\rangle,|\eta\rangle$ and $|\zeta\rangle$ state. ${ }^{22}$ Real et al. reported a compressed octahedral geometry for $\mathbf{1}$ and $\mathbf{2}$ based on crystal structure determination. ${ }^{4}$ The effect of low-symmetry ligand fields and spin-orbit coupling on the magnetic behaviour of transitionmetals with the ${ }^{5} \mathrm{~T}_{2 \mathrm{~g}}$ ground term has been reported. ${ }^{23}$ Electronic Raman transitions between low-lying electronic states have been detected for lanthanide and transition metal ions before, especially tetraphenylporphyrinatoferrate(III) complexes. $^{24}$

\section{Conclusions}

In the present study we investigated the influence of methyl and chloro substituents on the spin transition of $\left[\mathrm{Fe}\left(\mathrm{H}_{2} \mathrm{Bpz}_{2}\right)_{2}(\mathrm{phen})\right]$ (2) in the solid state and in films deposited from the gas phase. Importantly, thin film preparation is feasible for all compounds by thermal deposition, enlarging the library of iron complexes for physical vapour deposition. ${ }^{1,2,7,20,25}$ These systems thus offer the unique opportunity to investigate the thermal as well as light-induced SCO behaviour in the absence of solid-state effects such as cooperative or intermolecular interactions.

A particularly spectacular example for this aspect is the behaviour of compound 6, which shows SCO in a vacuumdeposited film but remains in the high-spin state over almost the entire temperature range in the crystalline bulk material. Although we do not have direct information about the crystal structure of solvate-free $\mathbf{6}$, we assume that the persistence of the high-spin state in the solid state is due to the formation of dimers through $\pi-\pi$ interactions between neighbouring 4,7-dimethyl-1,10-phenanthroline ligands which have been detected in the toluene solvate of 6 and in other $\left[\mathrm{Fe}\left(\mathrm{H}_{2} \mathrm{Bpz}_{2}\right)_{2}(\mathrm{~L})\right]$ complexes. ${ }^{12}$ If sufficiently strong these interactions can "lock" the system in the high-spin state. In microcrystalline powders of $\mathbf{6}$, these interactions are reduced. This allows an incomplete spin-transition to occur, as evidenced by optical and X-ray absorption spectroscopic measurements. In a vacuum-deposited film of $\mathbf{6}$ of several $100 \mathrm{~nm}$ thickness a full spin transition is observed, suggesting that the intermolecular interactions between the SCO molecules now are absent. On the other hand, for a film of $\sim 4$ ML of 6 on HOPG the spin transition again becomes incomplete. We believe that this is an effect of the surface on the spin transition of this complex, as observed for other systems. ${ }^{10}$

A second hallmark of the $\left[\mathrm{Fe}\left(\mathrm{H}_{2} \mathrm{Bpz}\right)_{2}(\mathrm{~L})\right]$ systems is the emergence of an electronic Raman transition at low temperature, as observed for compounds 1-6. This phenomenon, however, appears to be restricted to the crystalline bulk material because for the parent compounds $\mathbf{1}$ and $\mathbf{2}$ the corresponding bands are absent in vacuum-deposited films. As decomposition of 1 and 2 can be ruled out in the films, ${ }^{7}$ in analogy to compounds 3-6, we assume that the special packing of these complexes in the solid state and the emergence of electronic Raman transitions are connected with each other. Further investigation of this intriguing problem is underway. 


\section{Experimental}

All reactions were carried out in dry solvents and under an inert atmosphere. Functionalized 1,10-phenanthroline, iron(II) perchlorate hydrate and solvents were purchased commercially and used as supplied. Potassium dihydrobis-pyrazolylborate $\mathrm{K}\left[\mathrm{H}_{2} \mathrm{Bpz}_{2}\right]$ and the complexes were prepared according to literature methods. ${ }^{4,15}$

\section{Synthesis of $\left[\mathrm{Fe}\left(\mathrm{H}_{2} \mathrm{Bpz}_{2}\right)_{2}\right.$ (4-methyl-1,10-phenanthroline)] (3)}

To a solution of $\mathrm{Fe}\left[\mathrm{ClO}_{4}\right]_{2} \cdot 6 \mathrm{H}_{2} \mathrm{O}(726 \mathrm{mg}, 2 \mathrm{mmol})$ in methanol $(10 \mathrm{~mL})$ was added a solution of $\mathrm{K}\left[\mathrm{H}_{2} \mathrm{Bpz}_{2}\right](744 \mathrm{mg}, 4 \mathrm{mmol})$ in methanol $(10 \mathrm{~mL})$. The originated $\mathrm{KClO}_{4}$ precipitate was removed by filtration. A solution of 4-methyl-1,10-phenanthroline (388 $\mathrm{mg}, 2 \mathrm{mmol}$ ) in $10 \mathrm{~mL}$ methanol was added dropwise to the yellow $\mathrm{Fe}\left[\mathrm{H}_{2} \mathrm{Bpz}_{2}\right]_{2}$ solution. The solution was stirred for $15 \mathrm{~min}$ and a dark violet precipitate was collected, washed with methanol $(20 \mathrm{~mL})$, and dried under a stream of $\mathrm{N}_{2}$. Yield $786 \mathrm{mg} ; 72 \%$. Elemental analysis calculated for $\mathrm{C}_{25} \mathrm{H}_{26} \mathrm{~B}_{2} \mathrm{FeN}_{10}$ : C, 55.20; H, 4.82; N, 25.75. Found: C, 54.93; H, 4.79; N, 25.53.

\section{Synthesis of $\left[\mathrm{Fe}\left(\mathrm{H}_{2} \mathrm{Bpz}_{2}\right)_{2}\right.$ (5-chloro-1,10-phenanthroline)] (4)}

The method as reported for 3, using $\mathrm{Fe}\left[\mathrm{ClO}_{4}\right]_{2} \cdot 6 \mathrm{H}_{2} \mathrm{O}(160 \mathrm{mg}$, $0.44 \mathrm{mmol}), \mathrm{K}\left[\mathrm{H}_{2} \mathrm{Bpz}_{2}\right]$ (164 mg, $0.88 \mathrm{mmol}$ ) and 5-chloro-1,10phenanthroline ( $94.5 \mathrm{mg}, 0.44 \mathrm{mmol})$, yields a violet precipitate of 4. Yield $155 \mathrm{mg} ; 62 \%$. Elemental analysis calculated for $\mathrm{C}_{24} \mathrm{H}_{23} \mathrm{~B}_{2} \mathrm{ClFeN}_{10}$ : C, 51.07; H, 4.11; N, 24.82. Found C, 51.04; $\mathrm{H}, 3.98 ; \mathrm{N}, 24.56$.

\section{Synthesis of $\left[\mathrm{Fe}\left(\mathrm{H}_{2} \mathrm{Bpz}_{2}\right)_{2}(4,7-\right.$ dichloro-1,10-phenanthroline)] (5)}

The method as reported for 3, using $\mathrm{Fe}\left[\mathrm{ClO}_{4}\right]_{2} \cdot 6 \mathrm{H}_{2} \mathrm{O}(182 \mathrm{mg}$, $0.5 \mathrm{mmol}), \mathrm{K}\left[\mathrm{H}_{2} \mathrm{Bpz}_{2}\right](186 \mathrm{mg}, 1.0 \mathrm{mmol})$ and 4,7-dichloro1,10-phenanthroline $(125 \mathrm{mg}, 0.5 \mathrm{mmol})$, yields a violet precipitate of 5. Yield $209 \mathrm{mg} ; 70 \%$. Elemental analysis calculated for $\mathrm{C}_{24} \mathrm{H}_{22} \mathrm{~B}_{2} \mathrm{Cl}_{2} \mathrm{FeN}_{10}$ : C, 48.13, $\mathrm{H}, 3.70$; N, 23.39. Found: C, 47.97; H, 3.67; N, 22.99.

\section{Synthesis of $\left[\mathrm{Fe}\left(\mathrm{H}_{2} \mathrm{Bpz}_{2}\right)_{2}\right.$ (4,7-dimethyl-1,10-phenanthroline)] (6)}

The method as reported for 3, using $\mathrm{Fe}\left[\mathrm{ClO}_{4}\right]_{2} \cdot 6 \mathrm{H}_{2} \mathrm{O}(295 \mathrm{mg}$, $0.8 \mathrm{mmol}), \mathrm{K}\left[\mathrm{H}_{2} \mathrm{Bpz}_{2}\right](297 \mathrm{mg}, 1.6 \mathrm{mmol})$ and 4,7-dimethyl1,10-phenanthroline $(170 \mathrm{mg}, 0.8 \mathrm{mmol})$, yields a violet precipitate of 6. Yield $309 \mathrm{mg} ; 55 \%$. Elemental analysis calculated for $\mathrm{C}_{26} \mathrm{H}_{28} \mathrm{~B}_{2} \mathrm{FeN}_{10}$ : C, 55.96; H, 5.06; N, 25.10. Found: C, 56.49; $\mathrm{H}, 5.20 ; \mathrm{N}, 25.27$. The crystals of $6 \cdot 0.5 \mathrm{C}_{7} \mathrm{H}_{8}$ for single crystal analysis were grown by slow diffusion of $n$-hexane into a toluene solution.

\section{Single crystal structure analysis}

Data collections for $\mathbf{6} \cdot 0.5 \mathrm{C}_{7} \mathrm{H}_{8}$ were performed at three different temperatures using an imaging plate diffraction system (IPDS-2) from STOE \& CIE with Mo-K $\alpha$-radiation $(\lambda=0.71073 \AA$ A $)$. The structure solution was prepared by direct methods using SHELXS-97 and structure refinements were performed against $F^{2}$ using SHELXL-97. ${ }^{26}$ All non-hydrogen atoms were refined anisotropic. The $\mathrm{C}-\mathrm{H}$ and $\mathrm{B}-\mathrm{H} \mathrm{H}$ atoms were positioned with idealized geometry and refined isotropic with $U_{\text {iso }}(\mathrm{H})=1.2 U_{\text {eq }}(\mathrm{C}, \mathrm{B})$
(1.5 for methyl $\mathrm{H}$ atoms) using a riding model. The crystal structure contains an additional toluene molecule, which is disordered on a center of inversion. At room-temperature the disorder cannot be resolved and therefore, the data were corrected for disordered solvent using Squeeze in Platon but the toluene molecule was considered in the calculation of the molecular formula. At 200 and $110 \mathrm{~K}$ the disorder can be resolved and the toluene molecule was refined with a split model using restraints. CCDC $1054498\left(6 \cdot 0.5 \mathrm{C}_{7} \mathrm{H}_{8}\right.$ at $\left.293 \mathrm{~K}\right), 1054497\left(6 \cdot 0.5 \mathrm{C}_{7} \mathrm{H}_{8}\right.$ at $200 \mathrm{~K})$ and $1054497\left(6 \cdot 0.5 \mathrm{C}_{7} \mathrm{H}_{8}\right.$ at $\left.110 \mathrm{~K}\right)$.

\section{XA-spectroscopy}

The measurements were carried out in situ at a pressure of $8 \times$ $10^{-10} \mathrm{mbar}$ at the beamline UE56/2-PGM-1 of BESSY II. The photon flux at the sample position was about $10^{13}$ photons per s per $\mathrm{cm}^{2}$, with the energy resolution of the beamline set to $200 \mathrm{meV}$. XA spectra were recorded at the magic angle of 54.7 between the surface and the $k$ vector of the linearly $p$-polarized $\mathrm{X}$-rays. The absorption was measured in the total electron yield mode, where the sample drain current is recorded as a function of photon energy. The XA spectra were normalized with respect to a gold grid upstream to the experiment, and to the background signal from a clean HOPG substrate. The HOPG substrate $(12 \mathrm{~mm} \times 12 \mathrm{~mm})$ with a mosaic spread angle $(0.4 \pm 0.1)$ was purchased from Structure Probe. A clean HOPG surface was obtained by cleaving away layers of the surface in a vacuum $\left(10^{-6}\right.$ mbar) using carbon tape. The bulk sample was prepared by finely scratching molecular powder onto indium foil. The thin film $(4 \mathrm{ML})$ was prepared by evaporating the molecular powder from a tantalum Knudsen cell at about $460 \mathrm{~K}$ onto the substrate held at RT. The thickness of the film was monitored using a quartz microbalance during the evaporation.

\section{Other measurements}

Elemental analyses were performed using a Euro Vector CHNSO-element analyser (Euro EA 3000). Samples were burned in sealed tin containers by a stream of oxygen. IR spectra were recorded on a Bruker Alpha-P ATR-IR Spectrometer. The magnetic measurements were performed using a physical property measurement system (PPMS, Quantum Design) with a magnetic field strength of $1 \mathrm{~T}$. Diamagnetic corrections were applied with the use of the tabulated Pascal's constants. Mössbauer measurements were recorded using a self-assembled spectrometer using standard transmission geometry. XRPD of the bulk material were recorded on a X'PERT PRO PANalytical instruments with a Göbel mirror and a PIXcel detector using $\mathrm{Cu}$ radiation. For Raman spectroscopic measurements a Dilor XY-Raman spectrometer (Horiba) was used with an $\mathrm{Ar}^{+} / \mathrm{Kr}^{+}$mixed gas laser (Spectra Physics GmbH) operating at 647 and $514 \mathrm{~nm}$. The compounds were crimped in $\mathrm{KBr}$ or evaporated as films on quartz discs or on $\mathrm{Au} / \mathrm{Ti} / \mathrm{glass}$ substrates (thickness several $100 \mathrm{~nm}$ ) under the same conditions as reported in ref. 7. Au/Ti/glass substrates with a $50 \AA$ titanium base layer and a $1000 \AA$ evaporated gold film were purchased from EMF Corporation (Ithaca, NY). UV/Vis spectra were recorded using a Cary 5000 spectrometer in transmission geometry. For temperature dependence a CryoVac Kryostat with 
liquid nitrogen or helium cooling was used. For illumination experiments $3 \times$ LED Luxeon Typ LXML-PM01-0080 (519 nm) and $1 \times$ LED Roithner Laser Technik APG2C1-810 (810 nm) was used from Sahlmann Photochemical Solutions.

\section{Acknowledgements}

The authors thank the Deutsche Forschungsgemeinschaft (DFG) for funding this research through CRC 677 (Kiel) and 658 (Berlin). U. Cornelissen, S. Pehlke and J. Pick are acknowledged for Raman, infrared and CHNS measurements, H. Lühmann and M. Rasmussen for magnetic measurements, W. von Osten for Mössbauer spectroscopy, S. Permien for XRPD and I. Jeß for X-ray single crystal measurements. A. Britton, D. Krüger, and M. Kohlmann are acknowledged for their support, and W. Mahler for his technical support during the beamtime sessions on BESSY II.

\section{Notes and references}

1 T. G. Gopakumar, F. Matino, H. Naggert, A. Bannwarth, F. Tuczek and R. Bernd, Angew. Chem., Int. Ed., 2012, 51, 6262.

2 T. Miyamachi, M. Gruber, V. Davesne, M. Bowen, S. Boukari, L. Joly, F. Scheurer, G. Rogez, T. K. Yamada, O. Ohresser, E. Beaurepaire and W. Wulfhekel, Nat. Commun., 2012, 3, 938; M. Gruber, V. Davesne, M. Bowen, S. Boukari, E. Beaurepaire, W. Wulfhekel and T. Miyamachi, Phys. Rev. B, 2014, 89, 195415; G. Molnár, L. Salmon, W. Nicolazzi, F. Terki and A. J. Bousseksou, J. Mater. Chem. C, 2014, 2, 1360; O. Kahn and C. J. Martinez, Science, 1998, 279, 44; J. Dugay, M. Giménez-Marqués, T. Kozlova, H. W. Zandbergen, E. Coronado and H. S. J. van der Zant, Adv. Mater., 2015, 27, 1288.

3 M. A. Halcrow, Spin-Crossover Materials, Properties and Applications, John Wiley \& Sons, Ltd, New York, 2013; P. Gütlich, A. B. Gaspar and Y. Garcia, Beilstein J. Org. Chem., 2013, 9, 342-391.

4 J. A. Real, M. C. Munoz, J. Faus and X. Solans, Inorg. Chem., 1997, 36, 3008.

5 N. Moliner, L. Salmon, L. Capes and M. C. Munoz, J. Phys. Chem. B, 2002, 106, 4276.

6 A. L. Thompson, A. E. Goeta, J. A. Real and M. C. Muñoz, Chem. Commun., 2004, 1390-1391.

7 H. Naggert, A. Bannwarth, S. Chemnitz, T. von Hofe, E. Quandt and F. Tuczek, Dalton Trans., 2011, 40, 6364.

8 T. Palamarciuc, J. C. Oberg, F. El Hallak, C. F. Hirjibehedin, M. Serri, S. Heutz, J.-F. Létard and P. J. Rosa, J. Mater. Chem., 2012, 22, 9690.

9 T. G. Gopakumar, M. Bernien, H. Naggert, F. Matino, C. F. Hermanns, A. Bannwarth, S. Mühlenberend, A. Krüger, D. Krüger, F. Nickel, W. Walter, R. Berndt, W. Kuch and F. Tuczek, Chem. - Eur. J., 2013, 19, 15702.

10 B. Warner, J. C. Oberg, T. G. Gill, F. El Hallak, C. F. Hirjibehedin, M. Serri, S. Heutz, M.-A. Arrio, P. Sainctavit, M. Mannini, G. Poneti, R. Sessoli and P. Rosa, J. Phys. Chem.
Lett., 2013, 4, 1546; X. Zhang, T. Palamarciuc, J. F. Letard, P. Rosa, E. V. Lozada, F. Torres, L. G. Rosa, B. Doudin and P. A. Dowben, Chem. Commun., 2014, 50, 2255; A. Pronschinske, R. C. Bruce, G. Lewis, Y. Chen, A. Calzolari, M. BuongiornoNardelli, D. A. Shultz, W. You and D. B. Dougherty, Chem. Commun., 2013, 49, 10446.

11 E. Ludwig, H. Naggert, M. Kalläne, S. Rohlf, E. Kröger, A. Bannwarth, A. Quer, K. Rossnagel, L. Kipp and F. Tuczek, Angew. Chem., Int. Ed., 2014, 53, 3019.

12 R. Kulmaczewski, H. J. Shepherd, O. Cespedes and M. A. Halcrow, Inorg. Chem., 2014, 53, 9809.

13 M. Milek, F. W. Heinemann and M. M. Khusniyarov, Inorg. Chem., 2013, 52, 11585; M. Nihei, Y. Suzuki, N. Kimura, Y. Kera and H. Oshio, Chem. - Eur. J., 2013, 19, 6946; K. Katayama, M. Hirotsu, I. Kinoshita and Y. Teki, Dalton Trans., 2012, 41, 13465; J. Rudnik, H. Naggert, S. Schwarzer, F. Tuczek and I. Parchmann, CHEMKON, 2014, 21, 85.

14 P. Gütlich, A. Hauser and H. Spiering, Angew. Chem., Int. Ed., 1994, 33, 2024.

15 S. Trofimenko, J. Am. Chem. Soc., 1967, 89, 3170.

16 G. R. Desiraju and J. A. R. P. Sarma, Proc. - Indian Acad. Sci., Chem. Sci., 1986, 96(6), 599.

17 S. Schenker, A. Hauser and R. M. Dyson, Inorg. Chem., 1996, 35, 4676.

18 P. Chakraborty, M.-L. Boillot, A. Tissot and A. Hauser, Angew. Chem., Int. Ed., 2013, 52, 7139.

19 Correspondingly 5 and 6 undergo thermal SCO in homogeneous solution.

20 M. Bernien, D. Wiedemann, C. F. Hermanns, A. Krüger, D. Rolf, W. Kröner, P. Müller, A. Grohmann and W. Kuch, J. Phys. Chem. Lett., 2012, 3, 3431.

21 U. Fano, Phys. Rev., 1961, 124, 1866; U. Fano and J. W. Cooper, Phys. Rev., 1965, 137, 1364.

22 E. I. Solomon, E. G. Pavel, K. E. Loeb and C. Campochiaro, Coord. Chem. Rev., 1995, 144, 369; R. Zimmerman and H. Spiering, Phys. Status Solidi B, 1975, 67, 487.

23 B. N. Figgis, J. Lewis and G. Webb, J. Chem. Soc. A, 1966, 422.

24 L. Galich, H. Hückstädt and H. Homborg, J. Porphyrins Phthalocyanines, 1997, 1, 259; B. J. Kennedy, K. S. Murray, P. R. Zwack, H. Homborg and W. Kalz, Inorg. Chem., 1986, 25, 2539; S. Sievertsen, H. Schlehahn and H. Homborg, Z. Anorg. Allg. Chem., 1993, 619, 1064.

25 T. Mahfoud, G. B. Molnar, S. Cobo, L. Salmon, C. Thibault, C. Vieu, P. Demont and A. Bousseksou, Appl. Phys. Lett., 2011, 99, 053307; S. Shi, G. Schmerber, J. Arabski, J.-B. Beaufrand, D. J. Kim, S. Boukari, M. Bowen, N. T. Kemp, N. Viart, G. Rogez, E. Beaurepaire, H. Aubriet, J. Petersen, C. Becker and D. Ruch, Appl. Phys. Lett., 2009, 95, 043303; B. Schäfer, C. Rajnak, I. Salitros, O. Fuhr, D. Klar, C. SchmitzAntoniak, E. Weschke, H. Wende and M. Ruben, Chem. Commun., 2013, 49, 1098; I. Cimatti, S. Ninova, V. Lanzilotto, L. Malavolti, L. Rigamonti, B. Cortigiani, M. Mannini, E. Magnano, F. Bondino, F. Totti, A. Cornia and R. Sessoli, Beilstein J. Nanotechnol., 2014, 5, 2139.

26 G. M. Sheldrick, Acta Crystallogr., 2008, 64, 112. 